Société d'histoire de la révolution de 1848 et des

révolutions du XIXe siècle

49 | 2014

1814-1815. Expériences de la discontinuité

\title{
Pierre SINGARAVÉLOU [dir.], Les empires coloniaux.
} $X I X^{e}-X X^{e}$ siècle

Points Histoire, Paris, Le Seuil, 2013, 480 p. ISBN : 978-2-7578-2843-4.

10 euros.

M'hamed Oualdi

\section{CpenEdition}

Journals

Édition électronique

URL : http://journals.openedition.org/rh19/4809

DOI : $10.4000 /$ rh 19.4809

ISSN : $1777-5329$

Éditeur

La Société de 1848

Édition imprimée

Date de publication : 1 décembre 2014

Pagination : 246-248

ISSN : 1265-1354

Référence électronique

M'hamed Oualdi, «Pierre SINGARAVÉLOU [dir.], Les empires coloniauX. XIXe-XXe siècle », Revue d'histoire du XIXe siècle [En ligne], 49 | 2014, mis en ligne le 01 décembre 2014, consulté le 22 septembre 2020. URL : http://journals.openedition.org/rh19/4809; DOI : https://doi.org/10.4000/rh19.4809

Ce document a été généré automatiquement le 22 septembre 2020.

Tous droits réservés 


\section{Pierre SINGARAVÉLOU [dir.], Les empires coloniaux. XIX ${ }^{e}-X X^{e}$ siècle}

Points Histoire, Paris, Le Seuil, 2013, 480 p. ISBN : 978-2-7578-2843-4. 10 euros.

M'hamed Oualdi

\section{RÉFÉRENCE}

Pierre SINGARAVÉLOU [dir.], Les empires coloniaux. XIX ${ }^{e}-X X^{e}$ siècle, Points Histoire, Paris, Le Seuil, 2013, 480 p. ISBN : 978-2-7578-2843-4. 10 euros.

1 Les empires coloniaux constitue une porte d'entrée idéale pour qui veut s'initier aux récentes orientations et aux riches débats d'une histoire en pleine reformulation : celle de la colonisation et des empires modernes. Collectif, l'ouvrage échappe pourtant au travers des livres polyphoniques. Sous la direction de Pierre Singaravélou, les auteurs (Isabelle Surun, Armelle Enders, Hélène Blais, Sylvie Thénault, Claire Fredj, MarieAlbane de Suremain, Bouta Etemad, Emmanuelle Sibeud et Frederick Cooper) partagent une même vision historiographique : les empires coloniaux ne sont pas que des espaces de domination uniforme; ils furent aussi et surtout des cadres d'adaptations à cette domination, des lieux d'interactions parfois violentes et de négociations souvent asymétriques. Suivant ce fil conducteur, l'introduction et chacun des neuf chapitres sont d'une très grande qualité, à la fois clairs, riches et sophistiqués. Ils n'introduisent pas le lecteur à un récit évènementiel. Les auteurs se méfient à raison d'une narration qui ferait fi des spécificités locales. Ils s'en tiennent à une déclinaison cohérente de thèmes permettant de comparer les empires coloniaux européens, états-unien et japonais, d'en suivre les formations, les expansions et l'éclatement final. La trame du livre nous fait ainsi passer des conquêtes militaires à la formation des sociétés impériales et coloniales selon une approche contextualisée des notions de races, de classe et selon une vision panoramique des migrations de peuplement et de travail. Puis des sociétés, l'on en vient aux territoires, aux administrations, aux projets de 
«civilisation» et de développement. Les trois derniers chapitres examinent les économies coloniales, les cultures impériales, les révoltes et processus de décolonisation.

2 Qu'ils soient intéressés par l'Occident ou par les mondes extra-européens, les historiens et amateurs du XIX siècle verront bousculées, avec bonheur, certaines de leurs connaissances de base sur le sujet. La théorie du racisme biologique est un produit de ce siècle mais elle ne fut pas hégémonique: elle n'a pas effacé la polysémie du terme "race", interchangeable jusqu'au milieu du XIXe siècle avec ceux de "castes " et « classes» (p. 78-79). Second enseignement notable : les migrations d'Asiatiques dans le sillage des colonisations et des formations d'empires furent autrement plus massives que celles des Occidentaux. 30 millions d'Indiens et 51 millions de Chinois quittèrent leur foyer entre 1840 et 1940 contre 56 millions d'Européens à la même période. Les taux de retour ne cessèrent d'augmenter parallèlement au développement des transports et au « rétrécissement du monde » (p. 125-127). Il n'est pas jusqu'au modèle dual et si pédagogique de la cité coloniale divisée entre quartiers européens et quartiers indigènes qui ne soit discuté. Sont désormais mises en avant les marges urbaines et les fabriques non européennes des villes (p. 190).

Ces mêmes lecteurs s'initieront autant à de nouvelles problématiques qu'à une variété d'approches méthodologiques: histoire de l'environnement renouvelée à partir de l'étude des domaines coloniaux; reformulations des champs juridiques en contexte colonial avec des effets en retour sur les espaces métropolitains; nécessaire reconsidération des notions de collaborations et résistances. D'entre toutes ces voies, une des plus intéressantes consiste aujourd'hui à penser les rapports pratiques et théoriques entre génocides et colonisation avec notamment la naissance des «camps de concentration » en contexte colonial à la fin du XIXe siècle : à Cuba en 1896 et aux Philippines, deux ans plus tard (p.59-61). Autre orientation prometteuse : la réponse que les historiens doivent apporter aux économistes américains, tenants de l'approche néo-institutionnelle, et qui depuis les années 1990 ont voulu expliquer les inégalités du monde actuel par une lecture générale et donc peu contextualisée de situations coloniales (p. 339).

4 De manière plus globale, au terme de ce riche parcours, la question de fond, irrésolue y compris au sein de cet ouvrage, tourne toujours autour du degré d'emprise des pouvoirs coloniaux sur les sociétés qu'ils prétendaient dominer: l'impérialisme européen fut-il un tournant, une "matrice de la modernité » (p.336) ou fut-il contourné ou enveloppé par les sociétés colonisées? Le très stimulant chapitre d'Emmanuelle Sibeud sur les cultures impériales propose de répondre à cette question cruciale en repartant des acteurs, de leurs circulations entre registres culturels et des sens qu'« ils donnaient à leur pérégrinations » (p. 337). À un autre niveau, la magistrale réflexion de Sylvie Thénault sur l'État colonial et ses éventuelles spécificités, invite à penser, notamment à la suite de Jean-François Bayart et Romain Bertrand, la formation de cet État en prenant en compte les structures qui l'ont précédé : il s'agit d'historiciser ce processus afin d'inscrire le moment « colonial » dans une plus large réflexion.

On le voit, nombre d'auteurs de ces Empires coloniaux reconnaissent non seulement la capacité d'agir des populations colonisées mais également, selon l'heureuse expression de Pierre Singaravélou, des "formes vernaculaires de régulation sociale que les colonisateurs ne voient et ne comprennent» pas (p. 29). Démontrer cette fameuse agency et cette autonomie d'action est visiblement un processus en cours pour le sous- 
continent indien. Sous l'influence conjuguée des subaltern studies et d'une histoire globale, l'ouvrage le démontre à plusieurs reprises : des élites indiennes, préexistantes à la colonisation, ont renouvelé les industries locales du textile et de la sidérurgie; les négociants de cette aire furent aussi les agents d'une dynamique impériale propre, en dominant le commerce dans l'Afrique orientale britannique (p. 325 et 156).

6 Mais ce travail de recouvrement de logiques endogènes reste encore à mener pour l'Empire colonial français. Cela passe notamment, faut-il encore le souligner, par la connaissance non seulement des langues mais aussi des langages vernaculaires et véhiculaires. Entre ces langues et ces langages, les discours des populations colonisées ont notamment procédé du religieux. Or cette dimension d'identification qui ne se superpose pas à l'échelle d'observation impériale est peu explorée : elle semble sousestimée dans cet ouvrage déjà très riche. Hélène Blais, Sylvie Thénault et Frederick Cooper rappellent, chacun à leur manière, comment les résistances aux pénétrations coloniales en terres islamiques ont couvert de vastes espaces, selon un réseau étendu de sanctuaires et de guides spirituels. Le religieux ne constitue alors pas qu'une dimension $\mathrm{du}$ quotidien. C'est aussi un langage d'appartenance, une manière d'appréhender l'histoire, de créer des horizons d'attente et d'embrasser de vastes espaces. Ce dernier usage est ici fondamental. En introduction, Pierre Singaravélou distingue les empires coloniaux modernes de ceux qui les précèdent notamment par leur dimension ultramarine, par le grand éloignement entre la métropole et les colonies occupées. Mais outre qu'elle exclut arbitrairement d'autres expériences impériales modernes, dont l'expérience ottomane, cette définition est problématique en ce qu'elle est façonnée à partir du centre et du point de vue des métropoles coloniales. Repartir à l'inverse des colonisés, de ces autres " acteurs ", comme y invite à raison ce très utile ouvrage, amènerait certainement à proposer des appréhensions alternatives des espaces de pouvoirs et d'appartenances. 